\title{
Untangling the origin of ghost gear within the Maldivian archipelago and its impact on olive ridley (Lepidochelys olivacea) populations
}

\author{
M. Stelfox ${ }^{1,2, *}$, M. Bulling ${ }^{1}$, M. Sweet ${ }^{1,2}$ \\ ${ }^{1}$ Aquatic Research Facility, Environmental Sustainability Research Centre, University of Derby, DE22 1GB, UK \\ ${ }^{2}$ Olive Ridley Project, 11 Dane Close, Bramhall, Stockport, Cheshire, SK7 3LF, UK
}

\begin{abstract}
There is little documentation available on the impact of abandoned, lost or discarded fishing nets ('ghost nets') on turtle populations. Here, we utilise data collected over a 5 year period to assess (1) if a particular net type or characteristic was identifiable as entangling more turtles and (2) if particular fishing practices (i.e. types of nets) could be managed to reduce turtle entanglement in the Maldivian archipelago. A total of 131 turtles were entangled in the 752 reported ghost nets, and olive ridley turtles Lepidochelys olivacea appeared to be the most vulnerable (making up $97 \%$ of entangled turtles). However, we estimate that the 752 nets in this study, reported over a 51 month period, could have entangled between 3400 and 12200 turtles across the Indian Ocean prior to being detected in the Maldives. Mesh size, seasonality (i.e. north east monsoon), and the presence of floats were all identified as variables significantly affecting the likelihood of turtle entanglement. The probability of entanglement increased as the mesh size increased but decreased when floats were present. Additionally, turtles were more likely to be entangled during the north east monsoon when currents flow from east to west. Cluster analysis indicated that there were at least 11 broadly assigned net types found floating in the study area, and these were dominated by trawl and gill nets. Our analyses highlight the need for a detailed database of existing gear types coupled with gear marking to improve traceability of ghost nets in the Indian Ocean.
\end{abstract}

KEY WORDS: Olive ridley · Turtle $\cdot$ Ghost gear $\cdot$ Fishers $\cdot$ Ghost fishing $\cdot$ Ghost net $\cdot$ Entanglement

\section{INTRODUCTION}

Human activity is thought to impact every ecosystem on Earth (Halpern et al. 2008, Cardinale et al. 2012). Marine litter as a mechanism of impact is receiving increasing attention (Fossi et al. 2018, Karthik et al. 2018, Krishnakumar et al. 2018, Vlachogianni et al. 2018, Sweet et al. 2019). It has been estimated that abandoned, lost or discarded fishing gear (ALDFG or 'ghost gear') make up 10\% of this litter (Macfadyen et al. 2009). ALDFG, specifically ghost nets, can have major impacts on ecosystems and their biodiversity, entangling a vast array of species (Stelfox et al. 2016) in a continuous process

${ }^{*}$ Corresponding author: martin@oliveridleyproject.org referred to as ghost fishing (Smolowitz et al. 1978). Sea turtles are particularly vulnerable to this type of litter (Wilcox et al. 2016). Although non-target captures (bycatch) of sea turtles in active fishing gear has been studied and shown to have significant impacts on turtle populations (Bourjea et al. 2008, Wallace et al. 2010, Peckham et al. 2016, Lucchetti et al. 2017), the scale of impacts due to ghost nets is less well understood.

It is likely that the life history characteristics of turtles make them particularly vulnerable to entanglement in ghost nets. For example, sea turtles are poikilotherms (cannot directly regulate their own body temperature) and are therefore seen basking on

(C) The authors 2019. Open Access under Creative Commons by Attribution Licence. Use, distribution and reproduction are unrestricted. Authors and original publication must be credited. 
beaches (Whittow \& Balazs 1982), and juveniles have been observed using floating algal mats as a basking substrate (Nichols et al. 2001). Ghost nets may therefore act as an alternative floating substrate and an attractive option for turtles seeking to bask, resulting in entanglement. Juvenile sea turtles are also often attracted to floating algal mats (and therefore also the floating nets) as a source of food and shelter (Boyle \& Limpus 2008).

Although ghost nets are a global issue, geographic differences in ocean currents, climatic conditions and local fishing practices are likely to generate spatial heterogeneity in the impact on turtle populations. This is further complicated by the high degree of regional connectivity between ocean borders. For example, a genetics-based study on olive ridley sea turtles Lepidochelys olivacea caught in ghost nets around Australia highlighted a variety of different, and mostly unidentified, genetic lineages or haplotypes (Jensen et al. 2013), indicating that ghost nets were impacting several genetically distinct rookeries spanning large geographical ranges (Jensen et al. 2013). In the Indian Ocean there remains a sparsity of knowledge on turtle populations and the effects ghost nets have on these. Throughout this region, there is considerable spatial heterogeneity in the use of fishing gear. For example, purse seine fishing and the use of fish aggregating devices (FADs) dominate throughout much of the Western Indian Ocean (Davies et al. 2014), and pelagic gill nets and trawling are commonly utilised throughout the Arabian and Bay of Bengal ecoregions (Dar et al. 2017, Thomas et al. 2017, Jones et al. 2018, Samanta et al. 2018). An additional source of complexity affecting the distribution of ghost nets in the Indian Ocean is the complex weather patterns, driven by 2 major components; the north east (NE) monsoon (where surface geostrophic currents generally flow westward between November and April), and the south west (SW) monsoon (where surface geostrophic currents generally flow eastward between May and October; Shankar et al. 2002).

The construction of reliable statistical models relating environmental conditions, regional fishing practices, and patterns in ocean currents to turtle entanglement in ghost nets, would enable the design of more effective tools for management and mitigation of this threat to turtle populations. However, the cryptic and transboundary nature of ghost nets, the limited knowledge associated with environmental conditions at the time of entanglement and the identities of the fisheries that lose the gear in the first place, make such models difficult to construct. Indeed, studies which have tackled such questions (but have fo- cused on the effects of bycatch and turtle entanglement) utilise temporal data (Casale et al. 2017) combined with knowledge of the fishery responsible. For ghost nets, this information is simply unknown. To date, only one study has attempted to analyse the effect of ghorst net and turtle entanglement (Wilcox et al. 2015). These authors indicated that larger mesh sizes and lighter twine (indicative of pelagic gill nets) increased the probability of entanglements in the gulf of Carpentaria, Australia. They then used a model to estimate the scale of the issue and hypothesised that over 14600 turtles would have been caught in the 8690 nets sampled in their study, if these nets drifted for only one year (Wilcox et al. 2015).

Here, we aim to utilise data collected at multiple locations within the Maldives over a period of 5 years to develop statistical tools for modelling the probability of turtle entanglement. The geographical position of the Maldives (centred in the Indian Ocean) offers a rare opportunity to assess the spatial dynamics of ghost nets through regional connectivity. As fishing by nets (in the Maldives) is limited to bait fishing associated with the tuna fishery (Miller et al. 2017), it is reasonable to assume that a large proportion of the floating ghost nets in this region originate from neighbouring countries (Stelfox et al. 2015). Additionally, the atolls in the Maldives draw a perpendicular line across the direction of ocean currents, with the atolls and outer reefs acting as traps for floating debris (Stelfox et al. 2015). This therefore acts as a 'natural' sampling filter. Here, we build on the study by Wilcox et al. (2015) by developing a model in a new geographic area (Maldives) and including an aspect of seasonality (NE and SW monsoon) as a potential factor affecting the probability of turtle entanglement. Furthermore, we also investigate the applicability of a novel approach of clustering net characteristics to identify groupings of gear types found drifting into the Maldives.

\section{MATERIALS AND METHODS}

There are several statistical methodologies available for relating independent variables (in this instance characteristics of the nets and/or environmental factors) to the probability of a turtle entangling with a ghost net, all of which have comparative strengths and weaknesses. In this study, we therefore utilised a suite of methods (logistic regression, random forests and partitioning around medoids [PAM] clustering; detailed below). These methods were chosen as they have been extensively used in several research fields, 
are well understood mathematically, and represent a transition from traditional statistical methods, through machine learning, to exploratory methods. Additionally, they are relatively robust to outliers and can be effectively applied to smaller datasets.

The Olive Ridley Project (ORP) is a UK charity collecting data from citizen scientists on ghost net and turtle entanglements found in the Indian Ocean. Here we report on data that was collected in the Maldives between 2013 and 2017 (51 months in total). Ghost net characteristics thought to be potential factors affecting the probability of turtle entanglement, were collected opportunistically following a protocol developed by the International Union for Conservation of Nature (IUCN) and the ORP (see Table S1 in the Supplement at www.int-res.com/articles/suppl/n040p309_supp.pdf) (https://oliveridleyproject.org/report-a-ghost-net). All ghost nets were reported by citizen scientists when finding them on beaches and/or on their way to dive/snorkelling sites floating on the surface or entangled on shallow coral reefs inside the atolls of the Maldivian archipelago. The location and date of net discovery, and whether a turtle was entangled or not (with a species identification if known) were also recorded. Photographs accompanied each turtle entanglement to help validate species identification. Those with no photographs were excluded from further analyses. Moreover, only whole carcasses were recorded in this analysis, skeleton and bones were excluded because species could not be accurately identified. The majority of ghost nets were burnt or sent to landfill after data collection, with a small proportion recycled into bracelets. A second independent dataset $(\mathrm{n}=49$ nets) was also collected in the same way, but over a shorter period (September 2017 to January 2018). The second dataset was utilised as independent data for testing predictions derived from the final model (random forest, explained below) developed using the first dataset (see below). This independent dataset did not overlap the study period of the first dataset and nets were incinerated after data collection.

\subsection{Logistic regression}

Logistic regression used the generalised linear model (GLM) framework with a logit link function and binomial error distribution (Eq. 1). This relates explanatory variables (ghost net and environmental characteristics) to a binary response variable (entanglement, no entanglement) (McCullagh 1984). Thus, here the link function relates effects of net characteristics and seasons to the probability that a net will contain an entangled turtle. The link function is usually expressed in the form of the natural logarithm (log) of the odds (of a net containing a turtle):

$$
\log \left(\frac{\pi}{1-\pi}\right)=\beta_{0}+\beta_{1} x_{1}+\beta_{2} x_{2}+\ldots+\beta_{\mathrm{i}} x_{\mathrm{i}}
$$

where the left-hand term is the logit link, with $\pi$ being the probability of an event (entanglement) occurring. Therefore, the logit form is the log of the odds of an event occurring. The right-hand side is the standard linear regression form showing the effects ( $\beta$ coefficients) of each of the explanatory variables $\left(x_{1}, x_{2} \ldots x_{\mathrm{i}}\right)$ on the log of the odds. $\beta_{0}$ represents the expected log odds value when all independent continuous variables have value zero, and factor variables have their baseline value.

Two of the independent variables, mesh size $(\mathrm{min}=$ $10 \mathrm{~mm}$, $\max =9700 \mathrm{~mm}$, mean $=128.49 \mathrm{~mm}$ ) and twine diameter $(\min =0.1 \mathrm{~mm}, \max =15 \mathrm{~mm}$, mean $=$ $1.65 \mathrm{~mm}$ ) had very skewed distributions and were therefore log transformed prior to performing logistic regression. We added 1 to twine diameter before logging to keep values within the domain of the log function due to some being close to zero in the first instance.

An information theoretic approach (Akaike information criterion [AIC]; Akaike 1981) was used to select the minimum adequate model. This approach is regarded as being a more robust selection method than likelihood ratio tests (Burnham et al. 1995). Both forward and backward step-wise selection was used to ensure consistency in selection. The logistic regression provided a complimentary analysis to our random forest models (explained below). This allowed for exploratory analyses of the relationship between independent variables (Table S1) and turtle entanglement. A comparison of residual deviance and degrees of freedom indicated no problems with over or underdispersion.

\subsection{Building classifiers with rare events}

Random forests were chosen as a classification method as they are known to perform well on complex non-linear data, have few statistical assumptions, are relatively robust when dealing with missing data and automatically incorporate interactions in their construction (Faraway 2016). Additionally, such models have been utilised in similar studies of bycatch (Báez et al. 2014, Oliver et al. 2015, James et al. 2016). For these reasons, our random forest was selected as our final predictive model and used to calculate the probability of turtle entanglement. 
The choice of hyperparameters used in the construction of random forests can alter model output, with studies indicating that the number of parameters randomly sampled at each split in the tree $\left(\mathrm{m}_{\text {try }}\right)$ being the most influential hyperparameter improving performance (see Probst et al. 2018 for a review). In this study, $m_{\text {try }}$ was tuned based on a sequential range between 1 and 20 (20 representing the full set of independent variables). When using the same cross validation sets to tune model hyperparameters and estimate model performance, optimistically biased estimates are known to occur (Cawley \& Talbot 2010). To overcome this bias, a nested cross validation was conducted which allowed for hyperparameter tuning in the inner loop and an estimate of the overall model generalisation to be made on the outer loop (Varma \& Simon 2006). This ensured that no data was 'leaked' from the test set during model tuning. Inside both loops a stratified $k$-fold cross validation $(k=10)$ was performed. This allowed minority and majority cases to be present in each random fold. A combination of $F_{1}$ score (explained below) and sensitivity (tpr) and specificity (tnr) measures were used to assess the applicability of hyperparameter values and to evaluate model generalisation.

The best random forest classifiers (those most likely to generalise well on unseen data) were selected as those giving the highest $F_{1}$ score, closest to 1 . Sensitivity and specificity were then used as additional metrics to quantify rates of false negatives and false positives respectively.

All analyses were conducted using the statistical programming language R v3.4.2 (R Core Team 2018). Random forest classifiers were constructed using the 'randomForest' package (Liaw \& Wiener 2002), with variable selection done using the 'cforest' function in the 'party' package (Hothorn et al. 2006). The cforest algorithm does not show bias when a mix of categorical and continuous variables are used, unlike traditional variable importance measures for random forests (Strobl et al. 2008). $k$-fold cross validation ( $k=$ 10) was performed within the 'caret' package (Khun 2017). Variables used in the final random forest model were selected based on starting with 10 of the highest-ranking variables (according to the cforest function), and then removing one variable at a time until the highest $\mathrm{F}_{1}$ score was achieved.

\subsection{Dealing with rare events}

Rare events, such as ghost net entanglements, are a challenge when building classifiers. Many algo- rithms perform poorly with such data, typically resulting in the minority class (here turtle entangled) being ignored (King \& Zeng 2001). It is possible to use 'oversampling' (replicating observations from the minority class) and 'under-sampling' (removing observations from the majority class) to try and minimise the impact of the rarity of the event (Estabrooks et al. 2004). However, over-sampling can result in bias in the selection of the minority class, while under-sampling can result in a loss of important data (Weiss 2004). An alternative to these more traditional methods is the synthetic minority oversampling technique (SMOTE). This takes minority class observations and generates synthetic ones. These are based on randomly positioning 'new' values of the minority class along a Euclidean path within multi-parameter space, thereby joining pairs of locations of actual observations of the minority class (Chawla et al. 2002). SMOTE was used in this study on our random forest classifiers to adjust the class imbalance in order to ensure that there were equal numbers of entanglement and no-entanglement cases.

\subsection{Assigning fishing nets to fisheries}

Partitioning around medoids (PAM) was utilised to create clusters of net characteristics (Kaufman \& Rousseeuw 1990). PAM works in a similar way to $k$ means clustering but uses representative objects (here particular nets) as 'centres' of clusters. This contrasts with utilising locations in multi-dimensional space that do not correspond with a particular object. Medoids are identified based on minimised mean dissimilarity of an object and the other objects in the corresponding cluster. This has the effect of reducing the sensitivity of cluster designations to outliers. Dissimilarity distances were based on the Gower dissimilarity index to allow for mixed variables. Distances were calculated using the 'daisy' function in the 'cluster' package (Maechler et al. 2017). The average silhouette width (Rousseeuw 1987) was used to assess the validity of the PAM clustering. Silhouette width is a measure of how similar an object is to its own cluster. Values range between -1 and +1 , and a high value indicates that the object is well fitted to its cluster.

PAM clustering can be susceptible to finding the local maximum causing the preferential influence of categorical variables. To avoid this problem, we evenly weighted the numerical variables (mesh size and twine diameter) more heavily than the categori- 
cal variables and adjusted these until the silhouette width reached local maxima. The 'construction' variable was also weighted to allow monofilament fishing nets, rarely found in the Maldives, to influence the clustering. Categorical variables were treated as nominal values in the calculation of the Gower indices, and the 2 continuous variables (stretched mesh size and twine diameter) were treated as ratio scaled.

\section{RESULTS}

A total of 1069 ghost net fragments, entangling 7 green turtles Chelonia mydas, 18 hawksbill Eretmochelys imbricata, 1 leatherback Dermochelys coriacea, 348 olive ridley Lepidochelys olivacea and 3 unidentified sea turtles were reported. Due to limitations in the field not all ghost nets could be measured. Therefore, 752 ghost net fragments were analysed in total, of which 80 had 1 or more turtle(s) entangled (Fig. S1). A total of 131 sea turtles were entangled in the 752 reported ghost nets, olive ridley turtles made up $97 \%$ of turtles caught. A further 49 ghost nets entangling 7 olive ridley turtles were reported between September 2017 and January 2018. These latter data were utilised as the test set to assess the performance of our final predictive regression tree model. For more information on the ghost nets typically found in the Maldives please refer to Stelfox et al. (2015).

\subsection{Logistic regression}

Our stepwise logistic regression analyses identified mesh size, seasonality (i.e. NE monsoon), and presence of floats as variables significantly affecting the probability of turtle entanglement (Table 1). However, the estimated fit of the model was poor $(0.055$; pseudo- $\mathrm{R}^{2}$ following McFadden 1979).

The probability of entanglement increased as the log mesh size increased (Fig. 1) but decreased when floats were present. Additionally, the model indicated that turtles were more likely to be entangled during the NE monsoon when currents flow from east to west. Despite net colour (blue) having a marginally insignificant ( $p=0.08, \alpha=0.05)$ positive impact, this trait was still included in the model as the model had the lowest AIC value (348, with maximum AIC values of other models ranging up to $\mathrm{AIC}=368.49$ ), and we took a conservative approach given the complexities of the structure of the data.
Table 1. Estimated regression coefficients for the minimum adequate logistic regression model, estimating the probability of a ghost net having captured a turtle. The minimum adequate model was obtained from stepwise selection using the Akaike information criterion. Logmesh: log mesh size; blue: ghost nets made of blue material; floats: floats attached to ghost nets

\begin{tabular}{|lrcrc|}
\hline Coefficient & Estimate & SE & $Z$ & $\mathrm{p}$ \\
\hline Intercept & -4.021 & 0.673 & -5.979 & $<0.0001$ \\
Logmesh & 0.335 & 0.122 & 2.738 & 0.006 \\
NE monsoon & 0.568 & 0.256 & 2.219 & 0.027 \\
Floats & -0.917 & 0.247 & -3.709 & 0.0002 \\
Blue & 0.489 & 0.280 & 1.743 & 0.081 \\
\hline
\end{tabular}

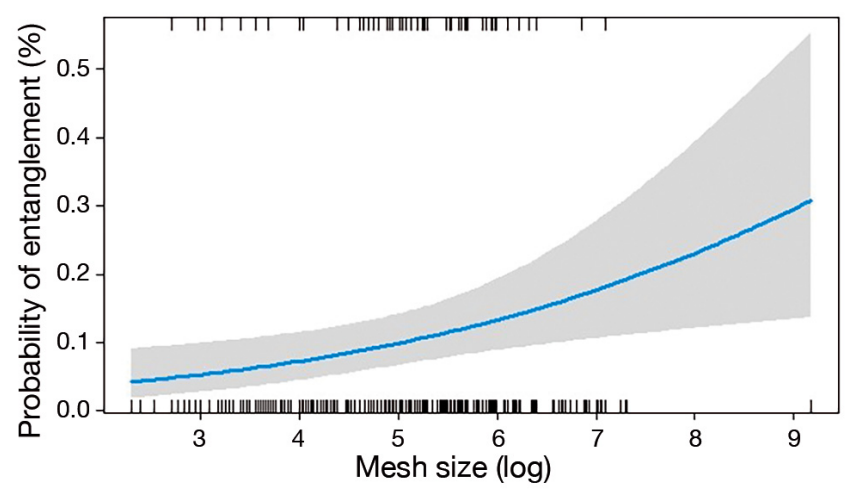

Fig. 1. Estimated effect of net mesh size on the probability of turtle entanglement (solid blue line) based on the minimum adequate logistic regression model. Black rugs at the top of the graph represent entanglement events, and rugs on the bottom represent no entanglement events. The positions of the rugs along the $x$-axis mark the log of the mesh size for the corresponding net. The grey band represents the $95 \%$ confidence intervals for the estimated probability

\subsection{Random forest model predictions}

Adjusting for class imbalance using SMOTE greatly improved the random forest model $\left(\mathrm{F}_{1}=0.24 \mathrm{com}\right.$ pared with $\left.F_{1}=0.04\right)$. Model generalisation was best when variables were reduced to the top 6 ranking variables (Fig. 2) $\left(\mathrm{F}_{1}=0.26\right.$, tpr $=0.66$, tnr $\left.=0.58\right)$.

Variable selection for the random forests generally complimented the final logistic regression model structure. However, twine diameter was judged to be an additional influential variable (Fig. 2).

A systematic grid search approach using the top 6 ranking variables did not show any convincing trends in effects on $\mathrm{m}_{\text {try }}$ selection (Fig. S2). Searching for the optimal value for $\mathrm{m}_{\text {try }}$ was inconclusive, and we used a value of 3, based on it resulting in the highest $F_{1}$ score $\left(F_{1}=0.30\right)$.

Our final model ( 6 top ranked variables and $\mathrm{m}_{\text {try }}=3$ ), when applied to the test data set, generalised to a 


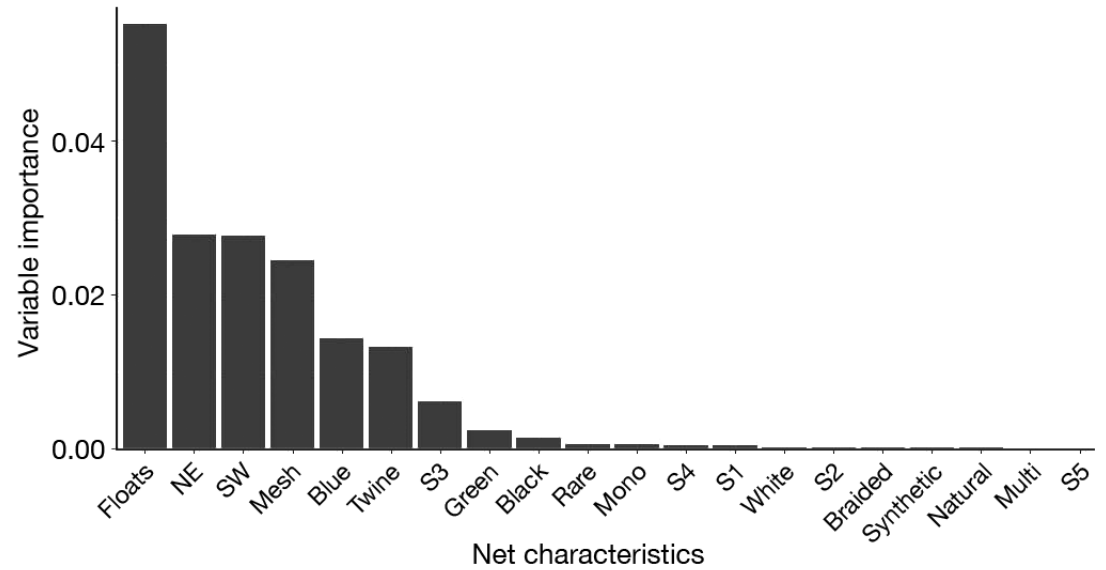

Fig. 2. Ranking (decreasing order) based on the influence of variables on the random forest model. Floats: floats attached to ghost nets; NE: north east monsoon; SW: south west monsoon; mesh: mesh size (mm); net colour (blue, green, black, white, rare colours [yellow, orange and red]); twine: twine diameter $(\mathrm{mm}) ; \mathrm{S} 1-\mathrm{S} 5$ : number of strands $(1-5)$; net construction (braided, multi[filament], mono[filament]); material (synthetic, natural) ent net clusters (0.65) amongst the 752 net fragments analysed in this study (Fig. S3).

Eight of these 11 clusters had greater average silhouette width, meaning that these 8 clusters are well assigned and likely to reflect true variation in net types. In contrast, the remaining 3 clusters (8, 10 and 11) showed incorrect or poorly assigned observations which subsequently reduced the average silhouette width (Fig. S4). While the heterogeneity within these 3 clusters was not large enough to warrant the addition of a cluster according to the average silhouette width, all their respective medoids had characteristics which were distinct from those of the other clusters (Table 2). For example, cluster 11 had similar extent to that of the model in the developmental stage $\left(F_{1}=0.32\right)$. The low sensitivity $(\mathrm{tpr}=$ $0.57)$ and higher specificity $(\mathrm{tnr}=0.66)$ demonstrate that the models are sensitive to type I errors. However, we were able to capture $63 \%$ of 'true' events, even though this was at the expense of an increase in the number of false positives (Fig. 3).

\subsection{Ghost net clustering}

The diversity of 'types' of net used within the Indian Ocean region is high. However, the average silhouette width gave statistical support for 11 appar-

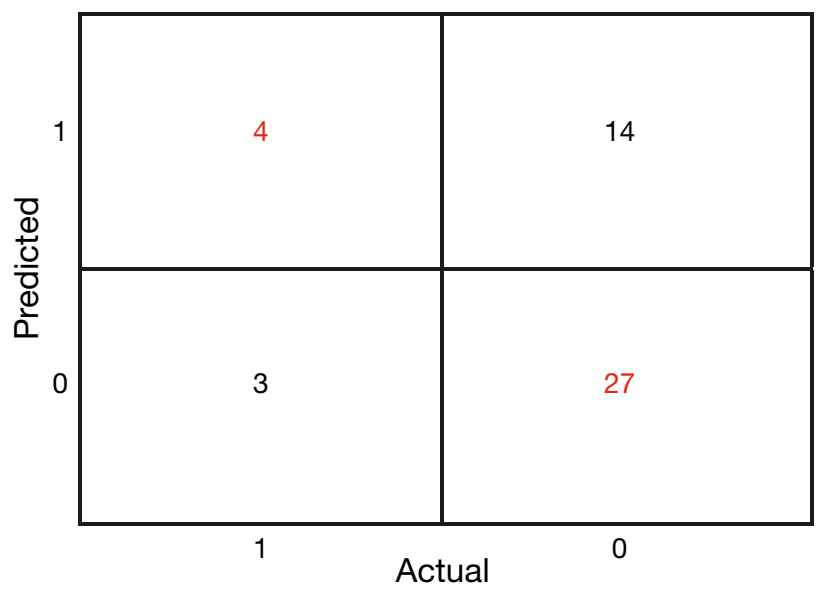

Fig. 3. Confusion matrix of the final random forest model on unseen data $\left(F_{1}=0.32\right)$. 0: no entanglement; 1 : entanglement. Red numbers indicate correctly identified observations. The proportion of false positives was 0.29 (14/48) only 1 observation which gave a negative silhouette width, and its characteristics are unlikely to be associated with any net in the Indian Ocean. Further, nets ( $\mathrm{n}=13$, Table 2 ) in cluster 8 had far heavier twine than the other clusters and, in contrast, nets in cluster 10 ( $\mathrm{n}=54)$ had a larger mesh size but light twine.

The bulk of observations were in the first 2 clusters and included most of the ghost nets which were predicted to have high probabilities of entangling turtles. Clusters showed a large overlap in mesh sizes, making it unlikely that individual clusters could be linked to specific fisheries (Fig. S5). For example, the heterogeneity in clusters 1, 2, 4, 6, 7 and 10 meant between gill and trawl nets among these clusters. However, the clustering did lead to some broad separations of net types based on net characteristics.

\section{DISCUSSION}

\subsection{Causes of turtle entanglement}

The results of the present study indicate that turtle entanglement is more likely to occur as the mesh size of a ghost net increases. This supports other studies conducted across Northern Australia (Wilcox et al. 2015) and the US mid-Atlantic region (Murray 2009). While the latter study focused on bycatch and not ghost net entanglement, this illustrates the importance of mesh size in relation to the entanglement of turtles on a global scale. In the present study, the majority of ghost nets encountered were largely that the clustering did not involve a clear distinction 
Table 2. Medoid characteristics showing the number of observations (n) assigned to each cluster. Turtle entanglements are shown as the total number of turtles entangled in each cluster (actual). The number of entangled turtles predicted by the random forest before type I error correction (predicted), and the number of entangled turtles predicted after the type I error correction (adjusted by $-29 \%$ ). FADs: fish aggregating devices; multi: multifilament; mono: monofilament; mesh: mesh size; twine: twine diameter

\begin{tabular}{|c|c|c|c|c|c|c|c|c|c|c|c|}
\hline \multirow[t]{2}{*}{ Net type } & \multirow[t]{2}{*}{ Cluster } & \multirow{2}{*}{ Mesh } & \multirow{2}{*}{ Twine } & \multirow{2}{*}{$\begin{array}{l}\text { Me } \\
\text { Strands }\end{array}$} & \multirow{2}{*}{$\begin{array}{l}\text { edoid val } \\
\text { Colour }\end{array}$} & \multirow{2}{*}{ Construction } & \multirow[b]{2}{*}{ Material } & \multirow[t]{2}{*}{$\mathrm{n}$} & \multicolumn{3}{|c|}{ — Turtle entanglements } \\
\hline & & & & & & & & & Actual & Predicted & Adjusted \\
\hline Gill/trawl & 1 & 75 & 1 & 3 & Blue & Multi & Synthetic & 259 & 23 & 59 & 42 \\
\hline Gill/trawl & 2 & 150 & 2 & 3 & Green & Multi & Synthetic & 204 & 23 & 65 & 46 \\
\hline FADs & 3 & 115 & 4 & 1 & Black & Braided & Synthetic & 21 & 2 & 9 & 6 \\
\hline Gill/trawl & 4 & 133 & 1.5 & 3 & Blue & Multi & Synthetic & 58 & 8 & 33 & 23 \\
\hline Gill net & 5 & 49 & 1 & 1 & White & Mono & Synthetic & 21 & 0 & 0 & 0 \\
\hline Gill/trawl & 6 & 260 & 3 & 3 & Green & Multi & Synthetic & 78 & 10 & 32 & 23 \\
\hline Gill/trawl & 7 & 275 & 4 & 3 & Blue & Multi & Synthetic & 41 & 6 & 19 & 14 \\
\hline Trawl net & 8 & 160 & 5 & 3 & Green & Multi & Synthetic & 13 & 2 & 7 & 5 \\
\hline Unknown & 9 & 1200 & 15 & 2 & Green & Multi & Synthetic & 2 & 0 & 0 & 0 \\
\hline Gill/trawl & 10 & 580 & 2 & 3 & Green & Multi & Synthetic & 54 & 6 & 12 & 9 \\
\hline Unknown & 11 & 9700 & 3 & 3 & Blue & Multi & Synthetic & 1 & 0 & 0 & 0 \\
\hline
\end{tabular}

damaged fragments which had likely been torn away from the main body of the net. Damaged smallmeshed nets may have an altered mesh size or large openings which could become problematic for sea turtles. Wilcox et al. (2015) highlighted that thinner twine was more likely to entangle turtles. Although this was not captured by our logistic regression, it was identified as a possible factor in the random forest analysis. Therefore, we suggest that although twine diameter does not appear to be a dominant variable explaining turtle entanglement it remains important for building predictive models, at least in this instance. Here, we also highlight that ghost nets found during the NE monsoon showed a significantly greater probability of having entangled turtles in them compared to ghost nets found in the counter currents generated from the SW monsoon. This supports previous studies which highlight the importance of seasonality and turtle entanglements in active fishing gear (Tomás et al. 2008, Kot et al. 2010). In the Indian Ocean, the NE monsoon coincides with peak nesting season for olive ridley turtles along the east coast of India (Pandav et al. 1997). Therefore, it is reasonable to assume that this results in an increase in turtle entanglement.

Surprisingly, ghost nets with no floats attached appeared to be more likely to entangle turtles. This contradicts studies focusing on active fishing gear and turtle entanglement which found the opposite trend, and which led to the suggestion of decreasing or removing floats from active fishing gear to reduce the probability of entanglement (Echwikhi et al. 2010, Gilman et al. 2010, Peckham et al. 2016). It could be hypothesised that the added buoyancy with floats may keep turtles at the surface for longer, giving them more time to escape. However, further work is needed to understand why this difference occurs and if management decisions need to take this into account.

Blue netting was also identified by the random forests as being a high-ranking variable, and was marginal in the logistic regression. Turtles have a well-developed sense of vision that clearly plays an important part in foraging behaviour (Swimmer et al. 2005, Southwood et al. 2008). However, most of our knowledge of sea turtle vision is derived from studies of loggerhead turtles Caretta caretta (Narazaki et al. 2013, Piovano et al. 2013) and Chelonia mydas (Mäthger et al. 2007). In contrast, no information on the visual capabilities for olive ridley turtles exists. It remains unknown if olive ridley turtles are more attracted to blue nets than those with other colours, or if blue nets remain invisible given their lack of contrast against the blue of the ocean. To the best of our knowledge, this is the first time that a possible link between turtle entanglement and ghost net colour has been made. However, the exact form and mechanism of the relationship remain to be identified and further research needs to be conducted to explore this.

Interestingly, in this study we estimate entanglement rates of $\sim 0.17$ (131/752), while in the most comparable study (Wilcox et al. 2015), rates were much lower ( 0.02). It is uncertain why the Maldives has significantly higher entanglement rates, but given their proximity to one of the largest aggregations of olive ridleys in the world (Shanker et al. 2004) this could be one major driver increasing the probability of entanglement. 


\subsection{Impact on sea turtles}

Our predictive models (random forest) estimated that 168 turtles ( $\mathrm{n}=236$ non-adjusted models) were entangled across all 752 ghost nets found during the course of this study. Although this number seems inflated when compared to the actual number of entanglements $(\mathrm{n}=80)$, it is important to consider that we only recorded ghost nets at the end of their life, and therefore we were unable to account for those turtles that managed to escape or decomposed prior to net stranding. Reports of turtle remains in ghost nets are not uncommon in the Maldives (Fig. 4) but there is little information on the decay rate of turtles in this region. Research in other areas of the tropics suggest that turtles may decay rapidly in only 5 to $18 \mathrm{~d}$ (Santos et al. 2018). With a decay rate of $5 \mathrm{~d}$, if we assume that on average nets drift for $1 \mathrm{yr}$ and turtles are evenly distributed across the region where ghost nets drift, then the portion of turtles entangled that could be detected would be $0.0137 \mathrm{yr}^{-1}$. Therefore, based on the predicted 168 turtles entangled, this suggests that 12200 turtles may have been entangled in the nets recovered over the length of our study (51 mo). With a decay rate of $18 \mathrm{~d}$ this drops to $\sim 3400$. These calculations are based on assuming an average behaviour of ghost nets, but it is impor-

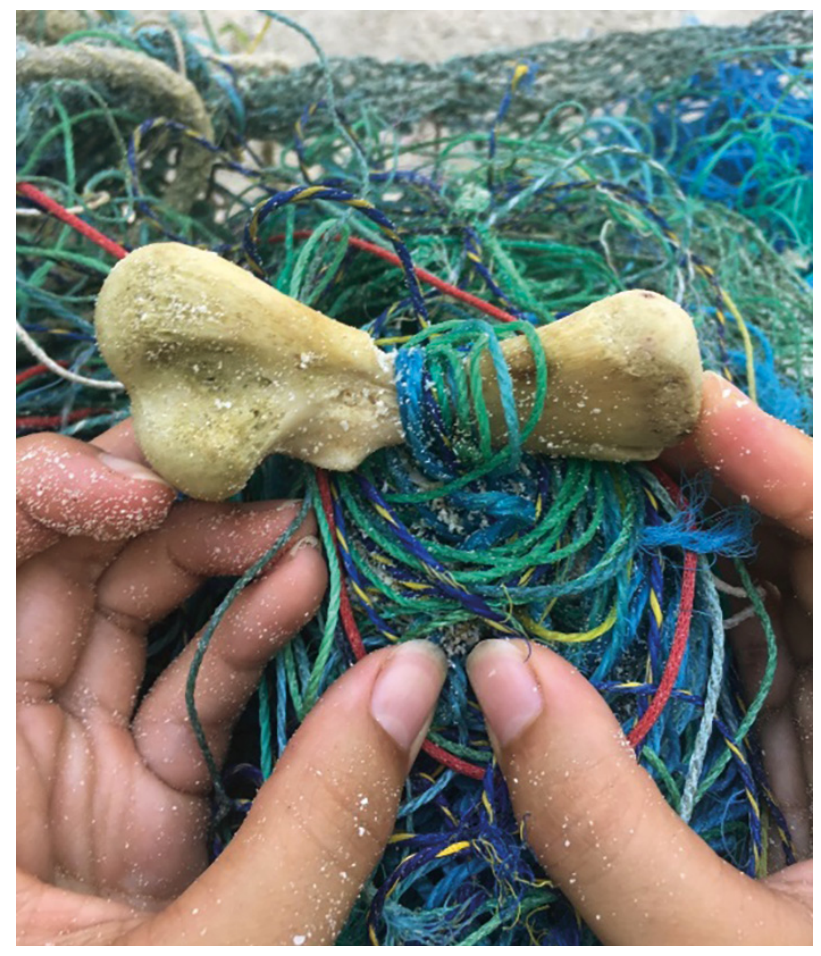

Fig. 4. Humerus bone of an unidentified species of sea turtle in the Maldives as an example of evidence of prior entanglement. Photo credit: Claire Petros tant to recognise that there is likely to be considerable temporal and spatial heterogeneity in the probability of encountering a net with an entangled turtle prior to the completion of decay. If we are to more accurately estimate entanglement probabilities and the true numbers of turtles being entangled, then 2 key parameters need to be quantified much more accurately: decay rates in the Indian Ocean and the actual number of ghost nets in the oceans at any particular time. Moreover, our random forest models have a relatively high false positive rate (0.29). Our dataset was imbalanced, particularly with respect to the number of entanglements compared with the number of non-entanglements. This is well known to produce high false positive rates. In an effort to address this issue we used SMOTE. Although this undoubtedly improved the situation, it is possible that some impacts of imbalance remained as a result of SMOTE not being completely effective.

\subsection{Potential origin of nets}

There is a general pattern of concern from artisanal fishers resulting from an increase in competition and conflict, leading to a loss of catch (Bennett et al. 2001, Whitmarsh et al. 2003). As a result, artisanal fishers have become increasingly opportunistic and carry multiple gear types during a single fishing trip. By doing so they can target different species and sizes, thus maximising fishing effort (Samoilys et al. 2017). A better understanding of the effects of ghost nets on turtle populations requires a much better knowledge of how many of the active nets become ghost nets. However, gaining such knowledge and identifying the origins of ghost nets is very difficult with the diversity of fishing gear design being utilised at local scales. Further, the complexity of ocean currents and surface movement driven by wind direction makes identifying ghost net origins considerably more difficult.

Our PAM analyses could not cluster net types according to fisheries and this could be explained by the similarities in gear type across fisheries and countries. For example, multifilament gill nets targeting seer fish, mackerel and pomfret in Mumbai, typically have light twine and mesh size ranging between 70 and $150 \mathrm{~mm}$ (Dar \& Thomas 2016). In contrast, drifting gill nets used to target Caranx sp. in Sri Lanka have mesh sizes ranging between 150 and $450 \mathrm{~mm}$ (Thivviyan \& Jayakody 2017). Therefore, in theory, these 2 fisheries should have separated out in the analysis. However, in Maharashtra, India gill nets 
targeting pomfret, mackerel and seer fish have light twine and mesh sizes ranging between 40 and $280 \mathrm{~mm}$. Similarly, trawl fisheries in Andhra Pradesh, India, have been reported to have a mix of net types, ranging between $20 \mathrm{~mm}$ at the codend to $2000 \mathrm{~mm}$ at the mouth of the net (Rajeswari et al. 2012). These overlaps within and between fishery types likely affect the ability of statistical methods to cluster net types according to fisheries. The same issues apply when trying to identify the geographical origin of the ghost nets. For example, if we aimed to ascertain where in the Indian Ocean ghost nets are coming from, we would need to be able to differentiate between major fishing districts. However, these fisheries predominantly use the same gear type. For example, of 2 surveys of fishing net types used in 2 different districts in India (Maharashtra) for gill nets (Nirmale et al. 2007) and Kerala for trawl nets (Sayana et al. 2016), both report mesh sizes ranging between 20 and $200 \mathrm{~mm}$. However, certain patterns and trends could be discerned from our data. For example, most nets reported in cluster 3 were dark braided nets. Upon closer inspection, fragments of bamboo were regularly associated with these nets (M. Stelfox pers. obs.) and these are consistent with FADs deployed predominantly in the western Indian Ocean and operated by fishers from the EU (Balderson \& Martin 2015). These nets are found in varying conditions, and occasionally trackers have been found to be attached, supporting these conclusions. Further, by adjusting weights in the model we were able to cluster rarely seen nets such as monofilament gill nets that are occasionally found in the Maldives (as in cluster 5). As highlighted above, these types of nets are widely utilised across many fisheries and many countries in the Indian Ocean. However, few were found in our surveys throughout the Maldives, and few of those had entangled turtles within. This may be because the density of nylon (the material commonly used to make monofilaments nets) is $1.14 \mathrm{~g} \mathrm{~cm}^{-3}$, meaning that it will sink in seawater. It is important to note that, although our study indicates that these nets are unlikely to be a major threat of entanglement, we are not suggesting that this implies any reduction in their effects on other marine life. Indeed, these nets are more likely to impact local fishing grounds and therefore be found close to fishing operations. Critically, the use of nets, other than for bait fishery, is banned in the Maldives. However, illegal fishing does occur due to lack of enforcement (M. Sweet pers. obs.), therefore some of the nets reported in this analysis may have actually been utilised in the Maldives.

\section{SOLUTIONS AND MITIGATION}

\subsection{Gear traceability}

Traceability of ghost nets was one of the major goals of this study. However, the complexity of usage of gear types used by fishers suggests that this is unlikely to be possible. The FAO have recognised that gear marking is a valuable method to improve traceability of ownership of gear types (FAO 2019). Moreover, methods such as barcoding, gear modification, radio frequency identification (RFID) and global positioning systems (GPS) can help improve traceability of lost fishing gear (He \& Suuronen 2018). However, these methods require significant human resources and can be expensive. One possible solution that may complement existing gear marking methods would be to utilise blockchain technology (Swan 2015) to improve traceability. Blockchain is a decentralised, immutable and distributed ledger that offers a transparent method to store data (Probst 2019). The blockchain would allow traceability of fishing nets from the fisher to the consumer at the end of the supply chain. Each transaction is stored as a 'block' and each new successive block makes up the blockchain ledger. This type of complex relationship has been reported to be handled very well by the blockchain technology (Swan 2016) and a pilot study is being performed to improve traceability of tuna caught in the Pacific Islands (Visser \& Hanich 2017). Utilising such technological advances may therefore help to close the gap on understanding what type of gear is being sold and where, identify high net sales, problem areas and potential red flags for certain gear types in a complex system with many stakeholders. Furthermore, the use of blockchain technology could be driven by consumer demand for more sustainable fisheries with greater accountability, leading to reduced gear loss associated with illegal, unreported and unregulated fishing activity.

\subsection{Ghost net prevention}

Our study clearly highlights the need for an urgent reduction in the loss of net fragments associated with gill and trawl net fisheries. However, the difficulties of implementing and enforcing such a broad recommendation in the region mean we may have to look at alternatives. An important first step would be to identify why gear is lost and develop solutions through information sharing among all stakeholders within the 
supply chain. Improved compliance on gear loss reporting by member countries of the Indian Ocean Tuna Commission (IOTC) may help determine which fisheries are facing the greatest challenge with regards to gear loss, which may help reallocate resources to minimise the issue from these fisheries.

The important role of seasonality in determining the probability of entanglement was highlighted by the model in this study. Therefore, there is an urgent need to identify migratory pathways of olive ridley turtles in the surrounding area to help pinpoint fishery overlap. Temporary closures in these overlapping areas during high turtle activity may reduce the likelihood of turtle entanglement as a result of gear loss caused by operational damage or general discard. Moreover, establishing free, port side or landing site recycling facilities would discourage small and largescale fishers from dumping damaged or end-of-life gear at sea. Given the large number of damaged and fragmented ghost nets reported in this analysis, buffer zones could be developed to ensure rugged bathymetric zones are avoided or controlled for, reducing gear damage and subsequent gear loss.

Finally, we have also demonstrated that net colour plays a role, albeit a relatively small one, in increasing the likelihood of sea turtle entanglement. However, more research will need to be conducted in order to understand this relationship before managerial decisions can be made on gear modifications related to net colour.

\section{CONCLUSION}

Although we cannot be sure how long ghost nets drift before being found in the Maldives, we have attempted to quantify the number of turtles entangled within this region and therefore highlight the level of threat faced by this one aspect of marine litter. Our results highlight that ghost net entanglement is likely a global issue and not a problem that individual countries will be able to deal with alone. Given the potential threat of ghost nets to sea turtles in the area we recommend that bycatch models account for gear loss to ensure that the impact that fisheries have on sea turtle populations is not underestimated. Future research on this topic should focus on methods to age ghost nets, for example, bioaccumulation rates so that this information can be fitted into models such as those outlined in this study. This will allow us to include drift times, allowing us to get one step closer to identifying the source of individual nets and reliably estimating the number of turtles entangled over the lifetime of a net. Our clustering models highlighted the continued need for gear loss reporting to researchers, charities and governmental agencies, enabling existing evidence regarding gear loss in the Indian Ocean to be gathered more effectively. There is an urgent need to advance our knowledge on gear types used by artisanal fishing communities. To this end, we recommend the construction of a detailed regional database of existing gear types so that positive identification of sources of ghost nets from artisanal fisheries may be possible. This could be coordinated by regional fisheries management organisations such as the IOTC. Finally, future resources should be focussed on a combination of improved gear traceability and the implementation of realistic measures to decrease gear loss in order to more effectively reduce amounts of ghost nets.

Acknowledgements. We thank the many scientists and volunteers of the ORP, particularly Dr. Jillian Hudgins, for their continued efforts to monitor and collect data on ghost nets in the Maldives. We also extend our gratitude to ORP and the IUCN for developing protocols for data collection of ghost nets in the Indian Ocean.

\section{LITERATURE CITED}

Akaike H (1981) Likelihood of a model and information criteria. J Econom 16:3-14

*Báez JC, García-Barcelona S, Mendoza M, de Urbina JMO, Real R, Macías D (2014) Cory's shearwater by-catch in the Mediterranean Spanish commercial longline fishery: implications for management. Biodivers Conserv 23: 661-681

Balderson SD, Martin LEC (2015) Environmental impacts and causation of 'beached' drifting fish aggregating devices around Seychelles Islands: a preliminary report on data collected by Island Conservation Society. IOTC WPEB, Victoria

* Bennett E, Neiland A, Anang E, Bannerman P and others (2001) Towards a better understanding of conflict management in tropical fisheries: evidence from Ghana, Bangladesh and the Caribbean. Mar Policy 25:365-376

Bourjea J, Nel R, Jiddawi NS, Koonjul MS, Bianchi G (2008) Sea turtle bycatch in the West Indian Ocean: review, recommendations and research priorities. West Indian Ocean J Mar Sci 7:137-150

* Boyle MC, Limpus CJ (2008) The stomach contents of posthatchling green and loggerhead sea turtles in the southwest Pacific: an insight into habitat association. Mar Biol 155:233-241

Burnham KP, White GC, Anderson DR (1995) Model selection strategy in the analysis of capture-recapture data. Biometrics 51:888-898

* Cardinale BJ, Duffy JE, Gonzalez A, Hooper DU and others (2012) Biodiversity loss and its impact on humanity. Nature 486:59-67

* Casale P, Abitsi G, Aboro MP, Agamboue PD and others (2017) A first estimate of sea turtle bycatch in the industrial trawling fishery of Gabon. Biodivers Conserv 26:2421-2433 
Cawley GC, Talbot NLC (2010) On over-fitting in model selection and subsequent selection bias in performance evaluation. J Mach Learn Res 11:2079-2107

Chawla NV, Bowyer KW, Hall LO, Kegelmeyer WP (2002) SMOTE: synthetic minority over-sampling technique. J Artif Intell Res 16:321-357

Dar SA, Thomas SN (2016) Design and general characteristics of five marine gillnets of Mumbai coast. Indian J Ecol 43:16-21

Dar SA, Desai AY, Sayani AN, Sharma J (2017) Design features of Seer fish gill nets operated by OBM along the selected landing centres of Junagadh District, Gujarat. Bull Env Pharmacol Life Sci 6:101-105

Davies TK, Mees CC, Milner-Gulland EJ (2014) The past, present and future use of drifting fish aggregating devices (FADs) in the Indian Ocean. Mar Policy 45:163-170

Echwikhi K, Jribi I, Bradai MN, Bouain A (2010) Gillnet fishery-loggerhead turtle interactions in the Gulf of Gabes, Tunisia. Herpetol J 20:25-30

Estabrooks A, Jo T, Japkowicz N (2004) A multiple resampling method for learning from imbalanced data sets. Comput Intell 20:18-36

FAO (2019) Voluntary guidelines on the marking of fishing gear. FAO, Rome. www.fao.org/3/ca3546t/ca3546t.pdf

Faraway JJ (2016) Extending the linear model with R: generalized linear, mixed effects and nonparametric regression models. Chapman and Hall/CRC, Boca Raton, FL

Fossi MC, Baini M, Panti C, Baulch S (2018) Impacts of marine litter on cetaceans: a focus on plastic pollution. Mar Mamm Ecotoxicol 2018:147-184

Gilman E, Gearhart J, Price B, Eckert S and and others (2010) Mitigating sea turtle by catch in coastal passive net fisheries. Fish Fish 11:57-88

Halpern BS, Walbridge S, Selkoe KA, Kappel CV and others (2008) A global map of human impact on marine ecosystems. Science 319:948-952

He P, Suuronen P (2018) Technologies for the marking of fishing gear to identify gear components entangled on marine animals and to reduce abandoned, lost or otherwise discarded fishing gear. Mar Pollut Bull 129:253-261

Hothorn T, Hornik K, Zeileis A (2006) Party: a laboratory for recursive partytioning [sic]. $\mathrm{R}$ package version 0.9-11. https://cran.r-project.org/package=party

James KC, Lewison RL, Dillingham PW, Curtis KA, Moore JE (2016) Drivers of retention and discards of elasmobranch non-target catch. Environ Conserv 43:3-12

Jensen MP, Limpus CJ, Whiting SD, Guinea M and others (2013) Defining olive ridley turtle Lepidochelys olivacea management units in Australia and assessing the potential impact of mortality in ghost nets. Endang Species Res 21:241-253

Jones BL, Unsworth RKF, Udagedara S, Cullen-Unsworth LC (2018) Conservation concerns of small-scale fisheries: by-catch impacts of a shrimp and finfish fishery in a Sri Lankan lagoon. Front Mar Sci 5:52

Karthik R, Robin RS, Purvaja R, Ganguly D and others (2018) Microplastics along the beaches of southeast coast of India. Sci Total Environ 645:1388-1399

Kaufman L, Rousseeuw PJ (1990) Finding groups in data: an introduction to cluster analysis. John Wiley \& Sons, Hoboken, NJ

Khun M (2017) caret: classification and regression training. R package version 6.0-77. https://cran.r-project.org/ package $=$ caret

King G, Zeng L (2001) Explaining rare events in interna- tional relations. Int Organ 55:693-715

Kot CY, Boustany AM, Halpin PN (2010) Temporal patterns of target catch and sea turtle bycatch in the US Atlantic pelagic longline fishing fleet. Can J Fish Aquat Sci 67: 42-57

Krishnakumar S, Srinivasalu S, Saravanan P, Vidyasakar A, Magesh NS (2018) A preliminary study on coastal debris in Nallathanni Island, Gulf of Mannar Biosphere Reserve, southeast coast of India. Mar Pollut Bull 131:547-551

Liaw A, Wiener M (2002) Classification and regression by randomForest. R News 2:18-22

* Lucchetti A, Vasapollo C, Virgili M (2017) An interviewbased approach to assess sea turtle bycatch in Italian waters. PeerJ 5:e3151

Macfadyen G, Huntington T, Cappell R (2009) Abandoned, lost or otherwise discarded fishing gear. FAO Fish Aquacult Tech Pap No. 523. FAO, Rome

Maechler M, Rousseeuw P, Struyf A, Hubert M, Hornik K (2017) cluster: finding groups in data. Cluster analysis basics and extensions. R package version 2.0.6. https:// cran.r-project.org/package=cluster

* Mäthger LM, Litherland L, Fritsches KA (2007) An anatomical study of the visual capabilities of the green turtle, Chelonia mydas. Copeia 2007:169-179

McCullagh P (1984) On the elimination of nuisance parameters in the proportional odds model. J R Stat Soc B 46: 250-256

McFadden D (1979) Quantitative methods for analysing travel behavior of individuals: some recent developments. In: Hensher DA, Stopher PR (eds) Behavioural travel modelling. Croom Helm, London, p 279-318

Miller KI, Nadheeh I, Jauharee AR, Anderson RC, Adam MS (2017) Bycatch in the Maldivian pole-and-line tuna fishery. PLOS ONE 12:e0177391

*Murray KT (2009) Characteristics and magnitude of sea turtle bycatch in US mid-Atlantic gillnet gear. Endang Species Res 8:211-224

Narazaki T, Sato K, Abernathy KJ, Marshall GJ, Miyazaki N (2013) Loggerhead turtles (Caretta caretta) use vision to forage on gelatinous prey in mid-water. PLOS ONE 8: e66043

Nichols WJ, Brooks L, López M, Seminoff JA (2001) Record of pelagic east Pacific green turtles associated with Macrocystis mats near Baja California Sur, Mexico. Mar Turtle Newsl 93:10-11

Nirmale V, Sontakki BS, Biradar RS, Metar SY, Charatkar SL (2007) Use of indigenous knowledge by coastal fisher folk of Mumbai district in Maharashtra. Indian J Tradit Knowl 6:378-382

\% Oliver S, Braccini M, Newman SJ, Harvey ES (2015) Global patterns in the bycatch of sharks and rays. Mar Policy 54: 86-97

Fandav B, Choudhury BC, Kar CS (1997) Mortality of olive ridley turtles Lepidochelys olivacea due to incidental capture in fishing nets along the Orissa coast, India. Oryx 31:32-36

* Peckham SH, Lucero Romero J, Maldonado Díaz D, Rodríguez Sánchez A, Senko J, Wojakowski M, Gaos A (2016) Buoyless nets reduce sea turtle bycatch in coastal net fisheries. Conserv Lett 9:114-121

* Piovano S, Farcomeni A, Giacoma C (2013) Do colours affect biting behaviour in loggerhead sea turtles? Ethol Ecol Evol 25:12-20

* Probst WN (2019) How emerging data technologies can increase trust and transparency in fisheries. ICES J Mar Sci 2019:fsz036 
Probst P, Bischl B, Boulesteix AL (2018) Tunability: importance of hyperparameters of machine learning algorithms. Stat 1050:26

R Core Team (2018) R: a language and environment for statistical computing. R Foundation for Statistical Computing, Vienna. www.r-project.org

Rajeswari G, Prakash RR, Sreedhar U (2012) Trawl designs used in small-scale mechanised fisheries sector of Andhra Pradesh, India. Fish Technol 49:18-27

Rousseeuw P (1987) Silhouettes: a graphical aid to the interpretation and validation of cluster analysis. J Comput Appl Math 20:53-65

Samanta R, Chakraborty SK, Shenoy L, Nagesh TS, Behera S, Bhoumik TS (2018) Bycatch characterization and relationship between trawl catch and lunar cycle in single day shrimp trawls from Mumbai coast of India. Reg Stud Mar Sci 17:47-58

Samoilys MA, Osuka K, Maina GW, Obura DO (2017) Artisanal fisheries on Kenya's coral reefs: decadal trends reveal management needs. Fish Res 186:177-191

Santos BS, Kaplan DM, Friedrichs MA, Barco SG, Mansfield KL, Manning JP (2018) Consequences of drift and carcass decomposition for estimating sea turtle mortality hotspots. Ecol Indic 84:319-336

Sayana KA, Remesan MP, Madhu VR, Pravin P, Edwin L (2016) Appraisal of trawl designs operated along Kerala coast. Fish Technol 53:30-36

Shankar D, Vinayachandran PN, Unnikrishnan AS (2002) The monsoon currents in the north Indian Ocean. Prog Oceanogr 52:63-120

Shanker K, Pandav B, Choudhury BC (2004) An assessment of the olive ridley turtle (Lepidochelys olivacea) nesting population in Orissa, India. Biol Conserv 115:149-160

Smolowitz RJ (1978) Lobster, Homarus americanus, trap design and ghost fishing. Mar Fish Rev 40:2-8

Southwood A, Fritsches K, Brill R, Swimmer Y (2008) Sound, chemical, and light detection in sea turtles and pelagic fishes: sensory-based approaches to bycatch reduction in longline fisheries. Endang Species Res 5:225-238

Stelfox MR, Hudgins JA, Ali K, Anderson RC (2015) High mortality of olive ridley turtles (Lepidochelys olivacea) in ghost nets in the central Indian Ocean. Bay of Bengal Large Marine Ecosystem (BOBLME) 2015 Ecology Report No. 14

Stelfox M, Hudgins J, Sweet M (2016) A review of ghost gear entanglement amongst marine mammals, reptiles and elasmobranchs. Mar Pollut Bull 111:6-17

Strobl C, Boulesteix AL, Kneib T, Augustin T, Zeileis A (2008) Conditional variable importance for random forests. BMC Bioinformatics 9:307

Swan M (2015) Blockchain: blueprint for a new economy. O'Reilly Media, Sebastopol, CA

Swan M (2016) Blockchain temporality: smart contract

Editorial responsibility: Mark Hamann,

Townsville, Queensland, Australia time specifiability with blocktime. In: Alferes J, Bertossi L, Governatori G, Fodor P, Roman D (eds) Rule technologies. Research, tools, and applications. Lect Notes Comput Sci, Vol 9718. Springer, Cham, p 184-196

* Sweet M, Stelfox M, Lamb J (2019) Plastics and shallow water coral reefs: synthesis of the science for policymakers. United Nations Environment Program, Nairobi

* Swimmer Y, Arauz R, Higgins B, McNaughton L, McCracken M, Ballestero J, Brill R (2005) Food color and marine turtle feeding behavior: Can blue bait reduce turtle bycatch in commercial fisheries? Mar Ecol Prog Ser 295: 273-278

Thivviyan S, Jayakody DS (2017) Assessment on the present status of coastal fisheries at Gurunagar, Jaffna. Vingnanam J Sci 12:18-31

* Thomas L, Venu S, Malakar B, Nagesh R, Basumatary G (2017) An assessment on the impact of bottom trawling to the demersal fisheries and benthic diversity of Andaman Islands, India. Reg Stud Mar Sci 10:20-26

*Tomás J, Gozalbes P, Raga JA, Godley BJ (2008) Bycatch of loggerhead sea turtles: insights from 14 years of stranding data. Endang Species Res 5:161-169

* Varma S, Simon R (2006) Bias in error estimation when using cross-validation for model selection. BMC Bioinformatics 7:91

Visser C, Hanich QA (2017) How blockchain is strengthening tuna traceability to combat illegal fishing. University of Wollongong

Vlachogianni T, Fortibuoni T, Ronchi F, Zeri C and others (2018) Marine litter on the beaches of the Adriatic and Ionian Seas: an assessment of their abundance, composition and sources. Mar Pollut Bull 131:745-756

Wallace BP, Lewison RL, McDonald SL, McDonald RK and others (2010) Global patterns of marine turtle bycatch. Conserv Lett 3:131-142

Weiss GM (2004) Mining with rarity: a unifying framework. SIGKDD Explor 6:7-19

*Whitmarsh D, Pipitone C, Badalamenti F, D'Anna G (2003) The economic sustainability of artisanal fisheries: the case of the trawl ban in the Gulf of Castellammare, NW Sicily. Mar Policy 27:489-497

Whittow GC, Balazs GH (1982) Basking behavior of the Hawaiian green turtle (Chelonia mydas) Pac Sci 36:129-140

Wilcox C, Heathcote G, Goldberg J, Gunn R, Peel D, Hardesty BD (2015) Understanding the sources and effects of abandoned, lost, and discarded fishing gear on marine turtles in northern Australia. Conserv Biol 29:198-206

Wilcox C, Mallos NJ, Leonard GH, Rodriguez A, Hardesty BD (2016) Using expert elicitation to estimate the impacts of plastic pollution on marine wildlife. Mar Policy 65:107-114

Submitted: May 14, 2019; Accepted: September 10, 2019 Proofs received from author(s): November 29, 2019 